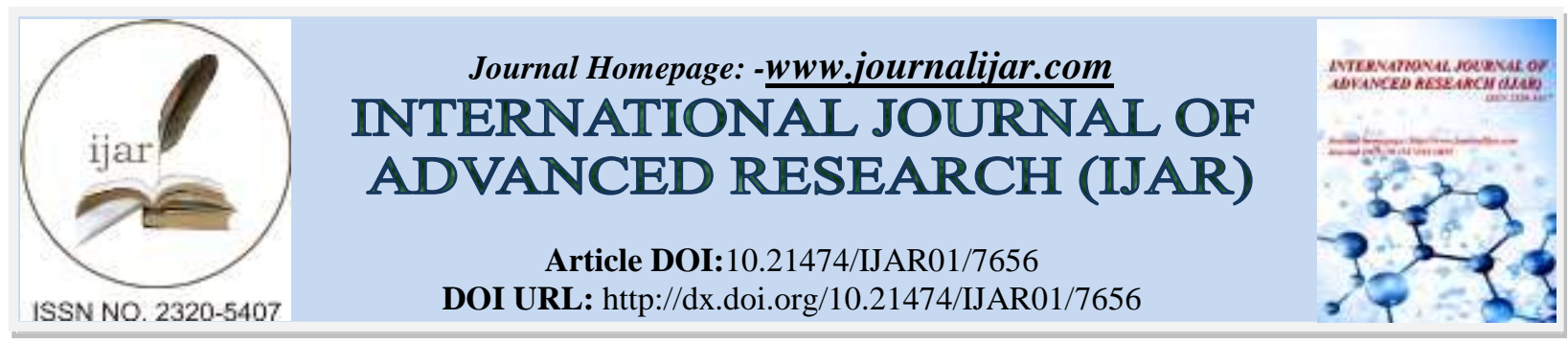

RESEARCH ARTICLE

\title{
INSILICO STRUCTURAL ANALYSIS AND DRUG DOCKING STUIDIES ON RIBULOSE -1, 5 BISPHOSPHATE CARBOXYLASE IN GRACILARIA EDULIS.
}

Shoba. K, Hebsibah Elsie. B and Jayakumari. S. Sathya. R.

Department of Biochemistry, D.K.M college for women (Autonomous), vellore,Tamilnadu, India.

\section{Manuscript Info}

Manuscript History

Received: 03 July 2018

Final Accepted: 05 August 2018

Published: September 2018

Keywords:-

Seaweed, Bioindicator, Rubisco,Calvin cycle, NCBI, Bioinformatics, Protein Modeling, Drug target.

\section{ABSTRACT}

Seaweeds are used in many countries as a source of food, for industrial applications and as a fertilizer. The major utilization of these plants as food is in Asia, particularly Japan, Korea, and china, where seaweed cultivation has become a major industry. The present uses of seaweeds at present are as human foods, cosmetics, fertilizers, and for the extraction of industrial gums and chemicals. They have the potential to be used as a source of long and short - chain substances may be extracted by fermentation and pyrolysis. The protein ribulose 1,5bisphosphate present in this algae. The enzyme is commonly referred to as rubisco. The limiting reaction within the Calvin Cycle is carried out by the enzyme Rubisco. The enzyme is located in the chloroplasts' stroma. The sequences of Rubisco retrieved from National Centre for Biotechnology Information in fasta format. Using BLAST p, the similarities of the target protein was searched. Modeled protein is evaluated through Rapper Server.

Copy Right, IJAR, 2018,. All rights reserved.

\section{Introduction:-}

Marine macroalgae, or seaweeds, are plant-like organisms that generally live attached to rock or other hard substrata in coastal areas. They belong to three different groups, empirically distinguished since the mid-nineteenth century on the basis of thallus color: brown algae (phylum Ochrophyta, class Phaeophyceae; see right for a large brown kelp, Durvillaea in New Zealand), red algae (phylum Rhodophyta; below Gelidium in Ireland), and green algae (phylum Chlorophyta, classes Bryopsidophyceae, Chlorophyceae, Dasycladophyceae, Prasinophyceae, and Ulvophyceae; bottom, Ulvahowensis in Lord Howe Island, off eastern Australia). Distinguishing these three phyla, however, involves more substantial differences than colour. In addition to the pigmentation, they differ considerably in many ultrastructural and biochemical features including photosynthetic pigments, storage compounds, composition of cell walls, presence/absence of flagella, ultrastructure of mitosis, connections between adjacent cells, and the fine structure of the chloroplasts. They originated through different evolutionary processes (primary endosymbiosis for green and red algae, secondary endosymbiosis for brown algae, and for this reason they are now classified in different kingdoms (green algae and red algae in the Kingdom Plantae, and brown algae in the Kingdom Chromista).

Seaweeds offer a wide range of therapeutic possibilities both internally and externally. The term Seaweeds in this case refers only to macrophytic marine algae, both wild and cultivated, growing in saltwater.Botanically, seaweeds are classified as Green, Brown, or Red. A particular seaweed's placement in one of these groups is determined first by its photosynthetic pigments, then its reproductive mode, then its micro and macro morphologies, and finally by its phycopolymers. The main red algal polymers are agar and carrageenan, and mainly porphyran in nori. All of

Corresponding Author:-Shoba .K.

Address:-Department of Biochemistry, D.K.M college for women (Autonomous), vellore,Tamilnadu, India. 
these polymers are sulfated galactans. They are modestly water-soluble, partially digestible and easily extracted from red seaweeds by boiling and seaweeds have a anti microbial, anti bacterial, anti inflammatoryactivities. The health benefits of seaweed include relief from cancer, obesity, diabetes, influenza, and radiation poisoning. It helps in improving digestive health, dental health, cardiovascular health, and maintaining healthy skin and hair. It protects eyes and has anti-coagulant properties. It also covers the body's need for iodine and helps in detoxification.

Most of the seaweeds are medium-sized and are available in multiple colors like red, brown, and green. They can be spotted ubiquitously on the seashores or coastlines.In addition to this, seaweed possesses anti-microbial and antiinflammatory properties that have been trusted for providing health benefits to humans from ancient times. It is a rich source of essential minerals such as magnesium, calcium, copper, potassium, selenium, zinc, iodine, and iron, while also containing a very low amount of fats. It is also a treasure trove of antioxidants, phytonutrients and rich fiber content that is required by the body. Vitaminspresent in seaweed are vitamin A, B, C, E, and vitamin K. It also contains omega-3 fatty acids and all the vital amino acids necessary for the body as per the WHO \& FAO guidelines.Extracts from macroalgae or seaweeds are rich in polyphenolic compounds which have well documented antioxidant properties.

\section{Matrials And Method:-}

The target sequence is retrieved from NCBI in FASTA format, Similarity of the target protein (Rubisco) is done through Blast P. CPH server used to predict the 3D structures of Rubisco. The predicted modeled target structures were validated using verified rapper server. Finally the modeled protein and de novo designed ligand were docked using Patch dock server, and results of docking were viewed through discovery studio.

\section{Results And Discussion:-}

The gracilariaedulis protein ribulose 1,5bisphosphate carboxylase, protein and nucleitide sequence were retrieved from National Centre for Biotechnology Information(NCBI) (figure 1). Compares an amino acid query against a protein sequence database by Blast $\mathrm{P}$ bioinformatics tool, the graphical representation of Blast $\mathrm{P}$ gives the alignment scores, in that graph, the red colour shows the high alignment score of the Rubisco(figure 2). The blast result shows the how well our query sequence matches with the subject in the database sequences. CPHmodels-3.0 is a webserver used to predict protein 3D-structure by use of single template homology modeling (figure 3). The server employs a hybrid of the scoring functions of CPHmodels-2.0 and a novel remote homology-modeling algorithm. A query sequence rubisco is first attempted modeled using the fast CPHmodels-2.0 profile-profile scoring function suitable for close homology modeling. The modelled structure was validated using RAPPER server and assessment of Ramachandran plot value shows (94.4\%). The $3 \mathrm{D}$ structure of designed de novo drug visualized using Discovery studio software. In Molecular drug studies, PatchDock server was used. Thus the molecular docking results show high affinity of rubisco protein. Our research would be useful for Clinical oncologists and Pharmacoinformaticians. The de novo drug would act as a potential therapeutic agent for various types of skin cancers.

NCBI:

PROTEIN:

>AAL46501.1 ribulose-1,5-bisphosphate carboxylase/oxygenase large subunit, partial (chloroplast)

[Gracilariaedulis]

RYESGVIPYAKMGYWDPNYAVKDTDILALFRVSPQPGVDPVEASAAVAGESSTATWTVVWTDLLTACDL $\mathrm{Y}$

RAKAYKVDAVPNTTDQYFAFIAYDIDLFEEGSIANLTASIIGNVFGFKAVKALRLEDMRIPVAYLKTFQG PATGLVVERERMDKFGRPFLGATVKPKLGLSGKNYGRVVYEGLKGGLDFLKDDENINSQPFMRWKERFL Y

SMEGVNRSIAATGEVKGHYMNVTAATMEDMYERAEFAKQLGTVIIMIDLVIGYTAIQTMGVWARKNDMI $\mathrm{L}$

HLHRAGNSTYSRQKIHGMNFRVICKWMRMAGVDHIHAGTVVGKLEGDPLMIRGFYNTLLLTHLDINLPQG IFFEQDWASLRKVTPVASGGIHCGQMHQLLDYLGNDVVLQFGGGTIGHPDGIQAGATANRVALEAMVLA $\mathrm{R}$

NEGRDYVAEGPQILRDAAKTCGPLQTALDLWKDITFNYTSTDTADFVETPTANV 
Fig 1:-The above result shows the fasta format of protein sequence of protein Ribulose 1,5 Bisphosphate Carboxylase.

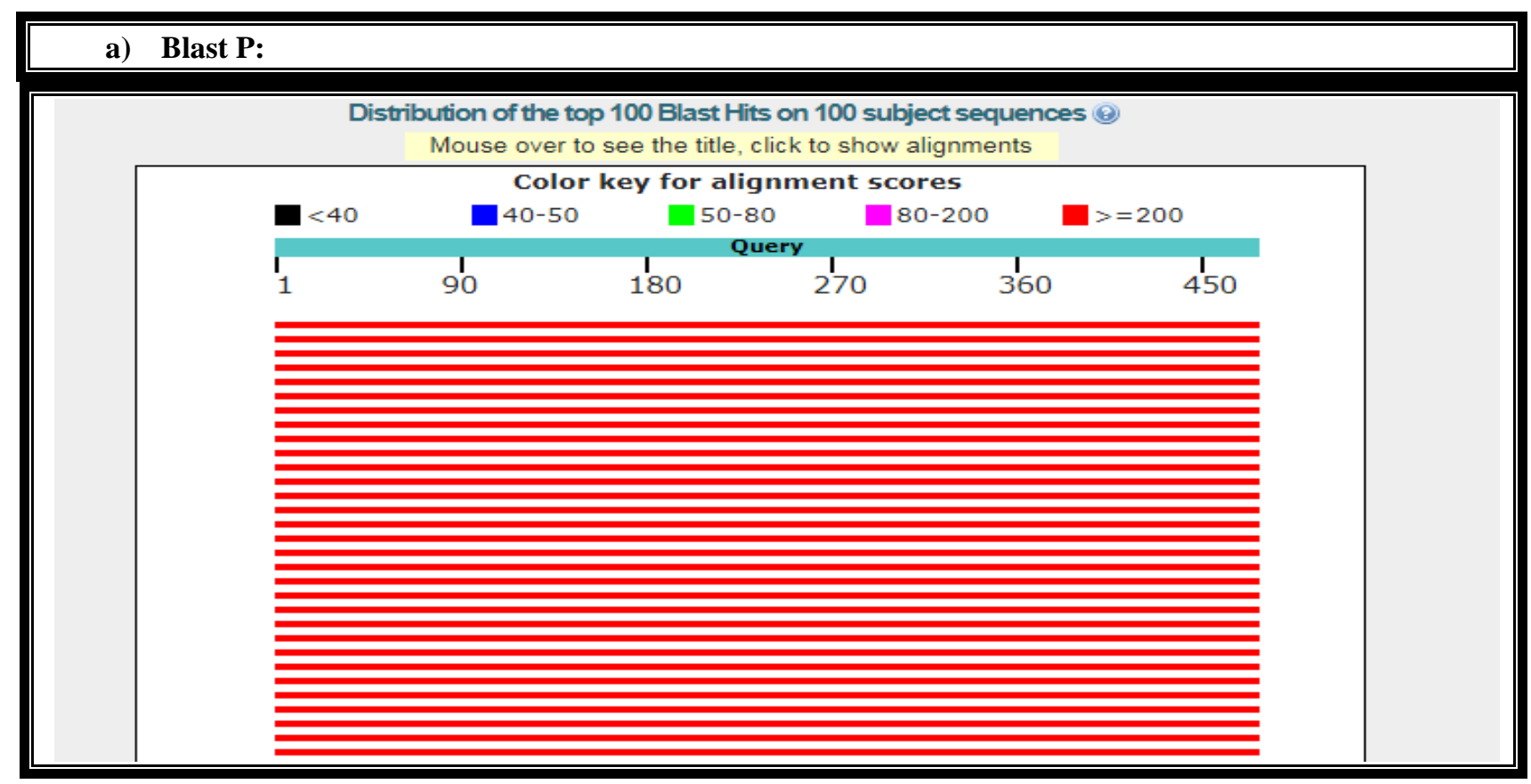

Fig 2:-Result shows the alignment score percentage and alignment of Rubisco protein.

Homology Modeling:-

\section{CPH:}

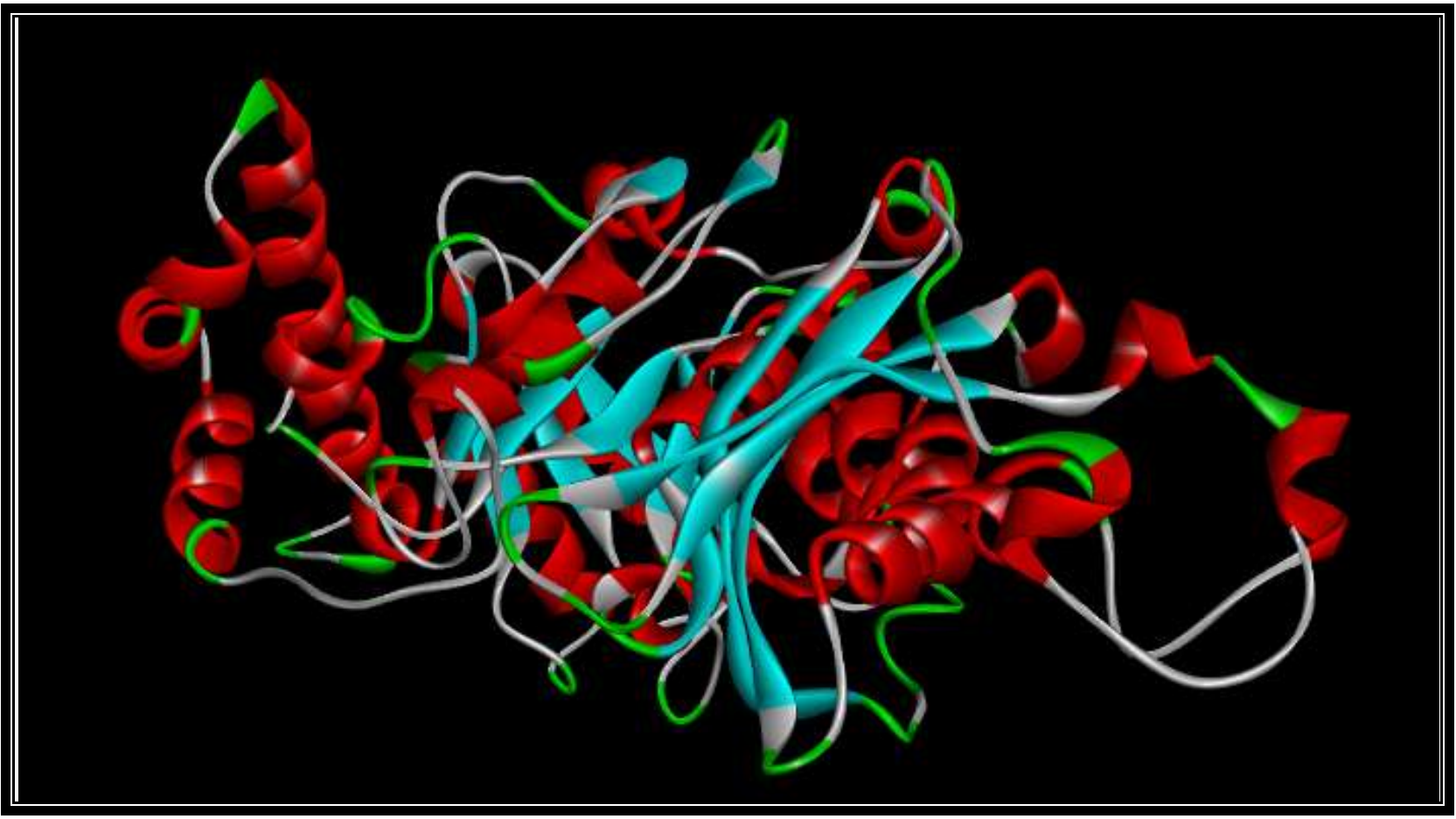



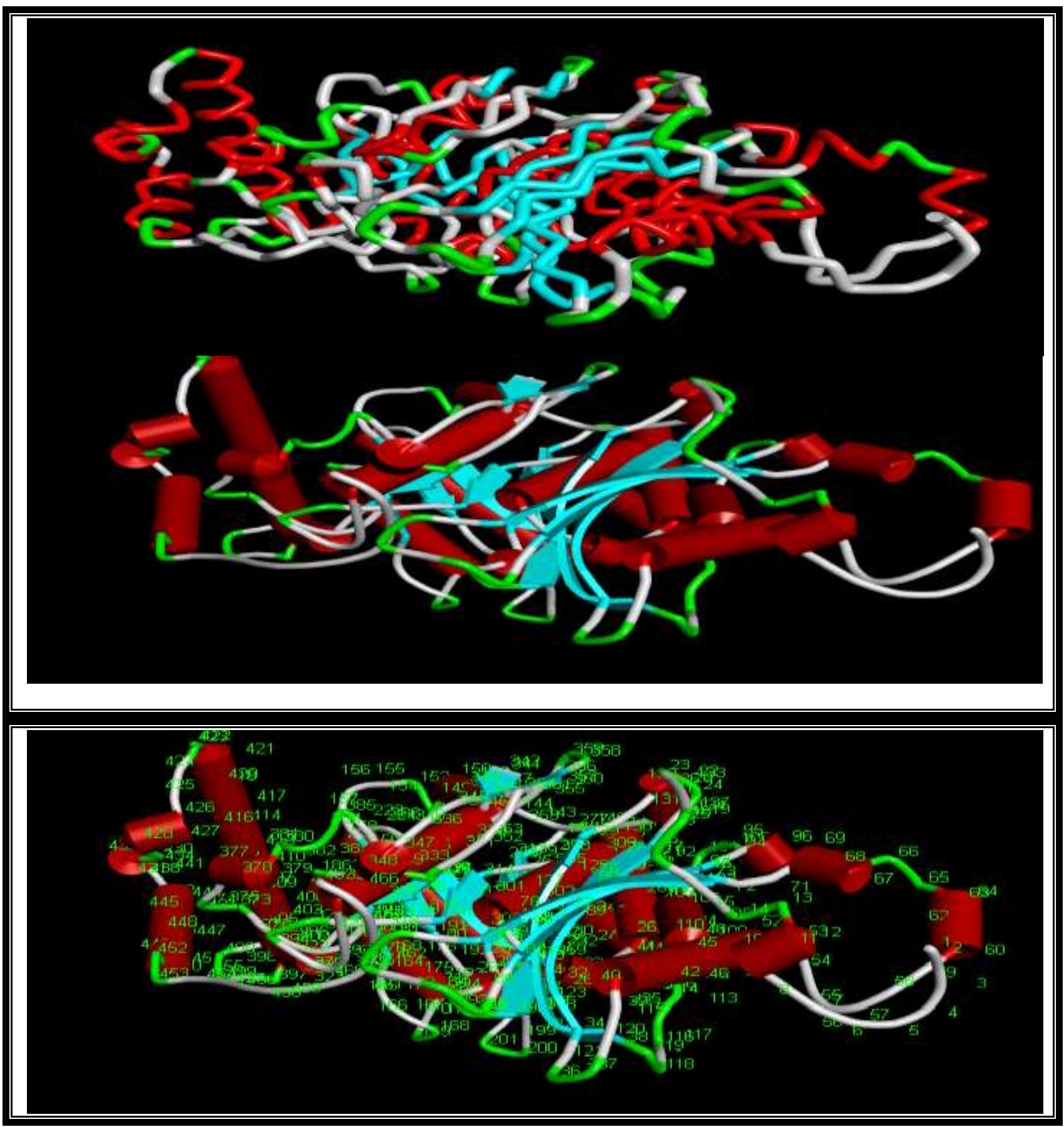

Fig 3:-The above result shows the 3D structure of Rubisco, the yellow color shows the sheets, pink color shows the helix, white colour shows the coiled region, blue colour shows the turns. 
Validation:-

Rapper Server
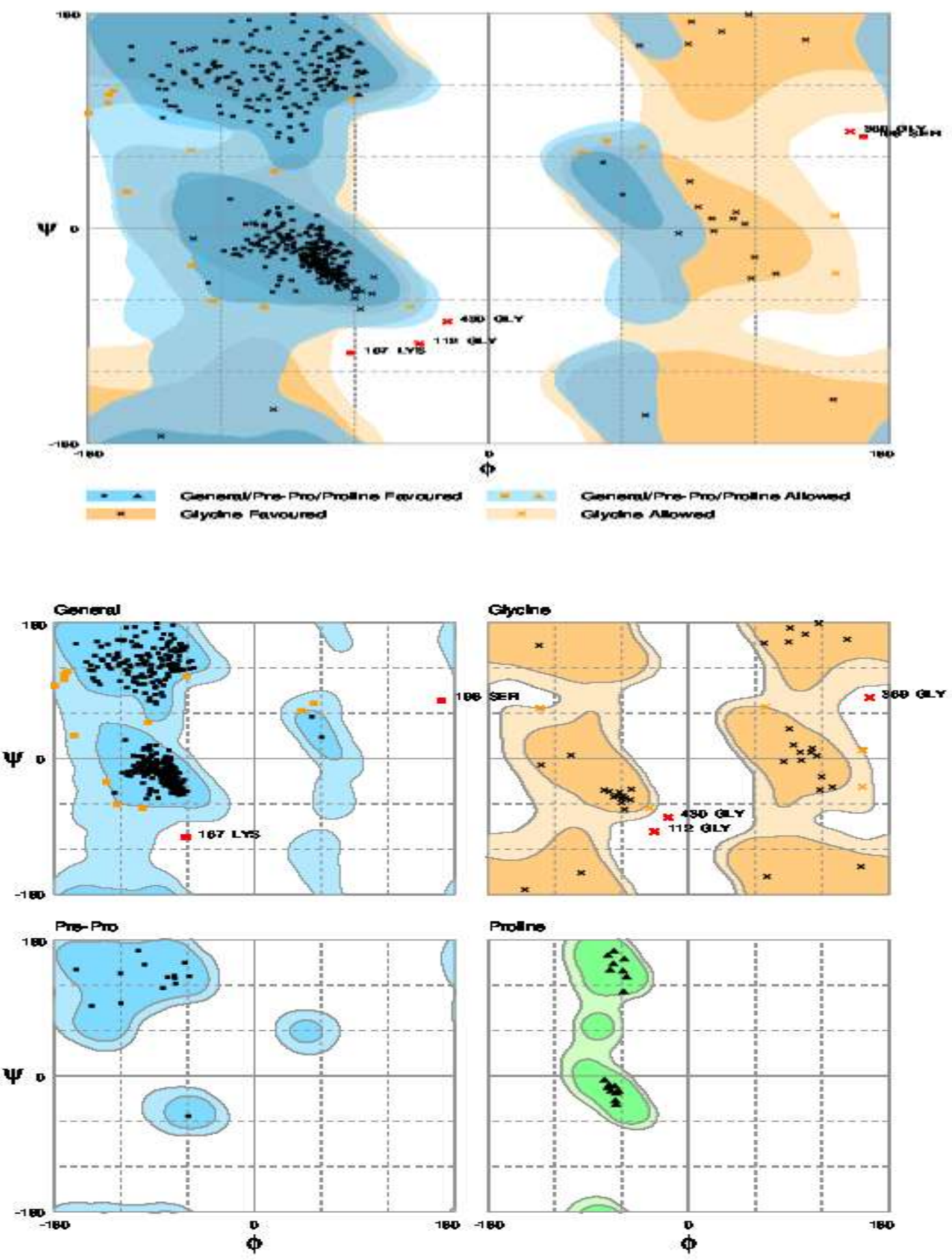

Prollns

Goneral Fewoured

Gyntro Fawounsd
Pre-Pho Fawounsd

Gyntro Fawounsd
Pre-Pho Fawounsd

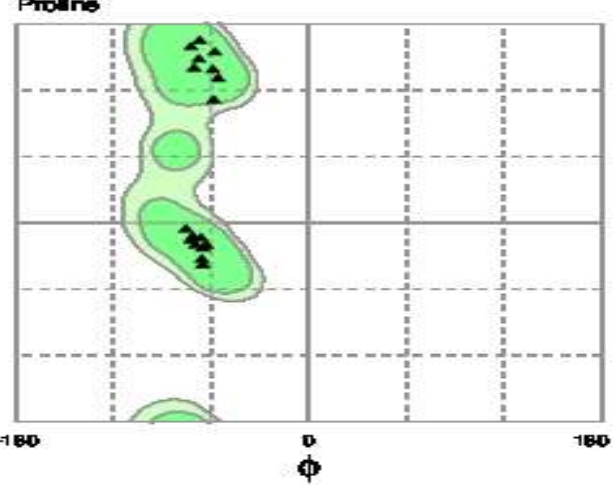

Coneral Allomed

Cyyane Allowed

Pre-Pro Allowed

Prollins Alomed

Fig 4:-The above results shows evaluation results of target protein. 


\section{Drug Target Analysis:-}

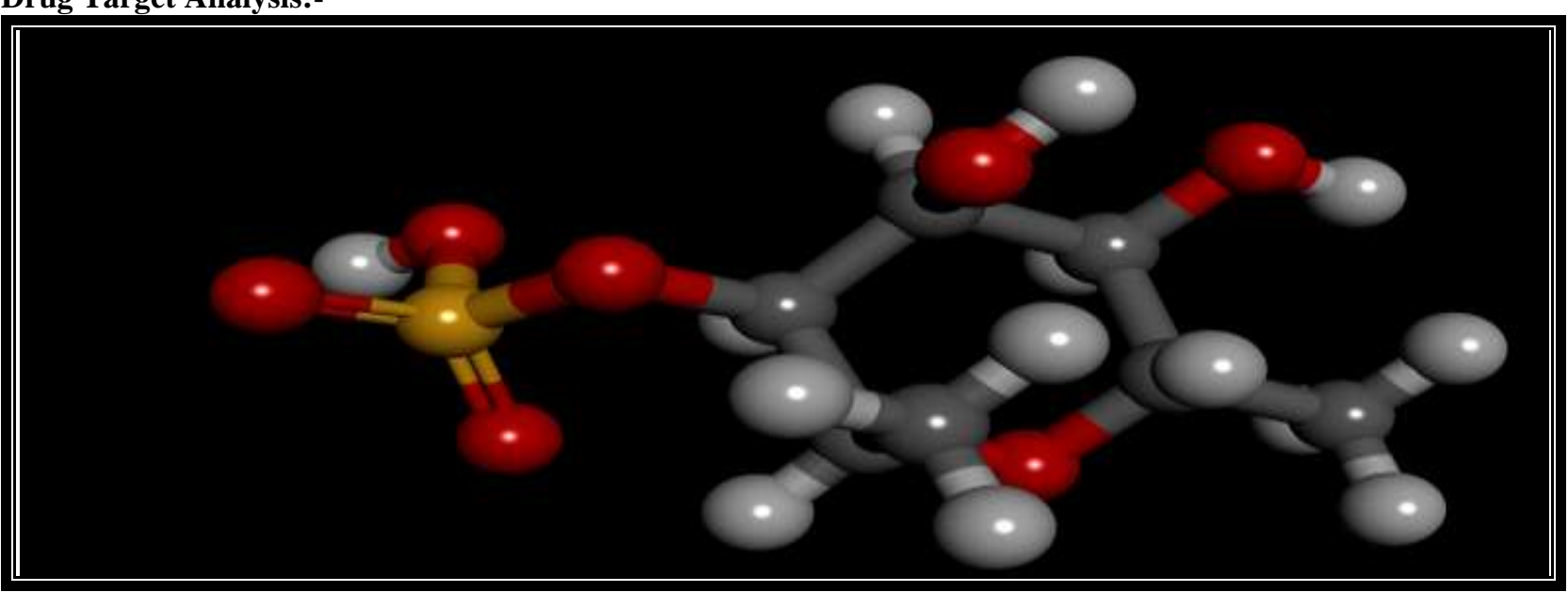

Fig 5:-The above results shows the ball and stick form of the drug

Protein Ligand Interaction:Discovery Studio

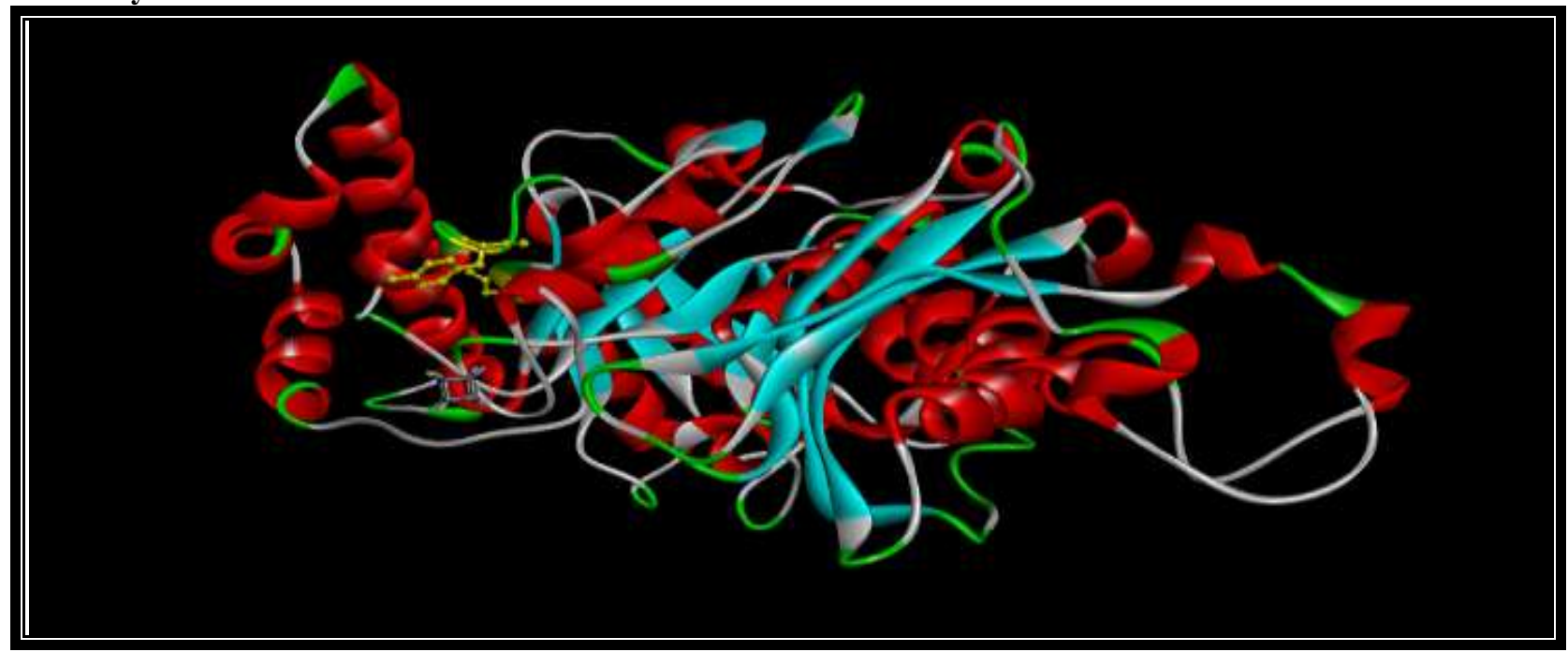

Fig 6:-The above results shows is the receptor and ligand interaction in different mode

\section{Conclusion:-}

Seaweeds are rich source of phytochemicals having antioxidant and antimicrobialproperties. Addition of seaweed to food enhances the antioxidant potential. Presence of fibers and minerals helps in improving the mineral content and reduce the salt content. And also seaweeds are used as fertilizer, composting, and potential source for bioethanol. Seaweed is an ingredient in toothpaste, cosmetics and paints. Sulfated saccharide from both red and green algae have been known to inhibit some DNA and RNA enveloped viruses. The rubisco is a important protein present in the seaweed gracilariaedulis.From the literature studies it shows that the ribulose-1, 5-bisphosphate carboxylase protein is one of the responsible anticancer proteins present in Gracilariaedulisseeweeds. Hence, it has been taken for various studies like protein primary structure analysis, Secondary structure analysis and protein three dimensional structure predictions. A comprehensive study of protein may be further used in research. 


\section{References:-}

1. Aceves C, Anguiano B, Delgado G. Is iodine a gatekeeper of the integrity of the mammary gland? J Mammary Gland BiolNeoplasia . 2005;10(2):189-196.

2. Cooper R, Dragar C, Elliot K, Fitton JH, Godwin J, Thompson K. GFS, a preparation of Tasmanian Undariapinnatifida is associated with healing and inhibition of reactivation of Herpes. BMC Complement AlternMed . 2002;2:11.

3. Damonte EB, Matulewicz MC, CerezoAS.Sulfated seaweed polysaccharides as antiviral agents.Curr Med Chem . 2004;11(18):2399-2419.

4. d'Ayala GG, Malinconico M, Laurienzo P. Marine derived polysaccharides for biomedical applications: chemical modification approaches. Molecules . 2008;13(9):2069-2106.

5. Feldman SC, Reynaldi S, Stortz CA, Cerezo AS, Damont EB. Antiviral properties of fucoidan fractions from Leathesiadifformis .Phytomedicine . 1999;6(5):335-340.

6. Frestedt JL, Kuskowski MA, Zenk JL.A natural seaweed derived mineral supplement (Aquamin F) for knee osteoarthritis: a randomised, placebo controlled pilot study. NutrJ . 2009;8:7

7. Johnson N. Seaweed and its synthetic analogues in obstetrics and gynaecology 450BC-1990AD. J R SocMed . 1990;83(6):387-389.

8. Nelson EA, Bradley MD. Dressings and topical agents for arterial leg ulcers. Cochrane Database SystRev .2007;(1):CD001836.

9. Liu JN, Yoshida Y, Wang MQ, Okai Y, Yamashita U. B cell stimulating activity of seaweed extracts.Int J Immunopharmacol . 1997;19(3):135-142.

10. Teas J, Baldeón ME, Chiriboga DE, Davis JR, Sarriés AJ, Braverman LE. Could dietary seaweed reverse the metabolic syndrome? Asia Pac J ClinNutr . 2009;18(2):145-154.

11. Teas J, Hurley TG, Hebert JR, Franke AA, Sepkovic DW, Kurzer MS. Dietary seaweed modifies estrogen and phytoestrogen metabolism in healthy postmenopausal women. J Nutr . 2009;139(5):939-944.

12. Shan BE, Yoshida Y, Kuroda E, Yamashita U. Immunomodulating activity of seaweed extract on human lymphocytes in vitro. Int J Immunopharmacol . 1999;21(1):59-70.

13. Shoba $\mathrm{k}$ and Vanitha $\mathrm{S}$, Gene expression analysis and molecular mechanics studies on collagenase protein in fiddler crab (uca) using insilico protocols. International journal of novel trends in pharmaceutical sciences, ISSN: 2277 -2782, volume 7, number 2, April 2017.

14. Shoba.k and Dr. Mazher sultana, Three - dimensional structure and motif prediction studies on collagenase protein in fiddler crab, International journal of novel trends in pharmaceutical sciences, Issn: 2277 2782, volume 6, issue 4, pages $79-83$.

15. Shoba K. , Manjuladevi M , Dr. Mazher sultana, Biochemical analysis and gene expression profiling on collagenase protein in fiddler crab, World journal of pharmacy and pharmaceutical sciences, issn 2278 - 4357, volume 6 , issue $3,747-756$

16. Shoba K. , Sowmiya S and Dr. Mazher sultana, World Journal of Pharmaceutical and Life Sciences, ISSN 2454-2229, Vol. 3, Issue 1, 427-436.

17. Shoba.K, Hebsibahelsie.B, insilico homology modeling ofribulose-1, 5-bisphosphate carboxylase protein in gracilariaedulis, world journal of pharmacy and pharmaceutical sciences, 2017, volume 6, issue 8, 396-406, issn $2278-4357$.

18. Shoba.K, Lavanya.G, Identification Of De Novo Peptide And Motif Prediction On Porphyria Protein (Hmbs) Using Insilico Tools, Universal Journal Of Pharmacy ,2018, Volume 8, Issue 1, Issn2320-303x.

19. Shoba.K, Lavanya.G, Tertiary Structural Prediction And Drug Binding Studies On Mutated Gene (Hmbs) In Human Porphyria,International Journal Of Novel Trends In Pharmaceutical Science,2018, Issn 2277 2782, Volume 8,Issue 1.

20. Shoba K., Hebsibah Elsie B. And Bavyasri S. Insilico Peptide Modeling Stuidies And Structural Analysis On Ribulose -1, 5 Bisphosphate Carboxylase In GracilariaEdulis, World Journal Of Pharmacy And Pharmaceutical Sciences, 2018,Volume 7, Issue 3, 1086-1095, Issn 2278 - 4357. 